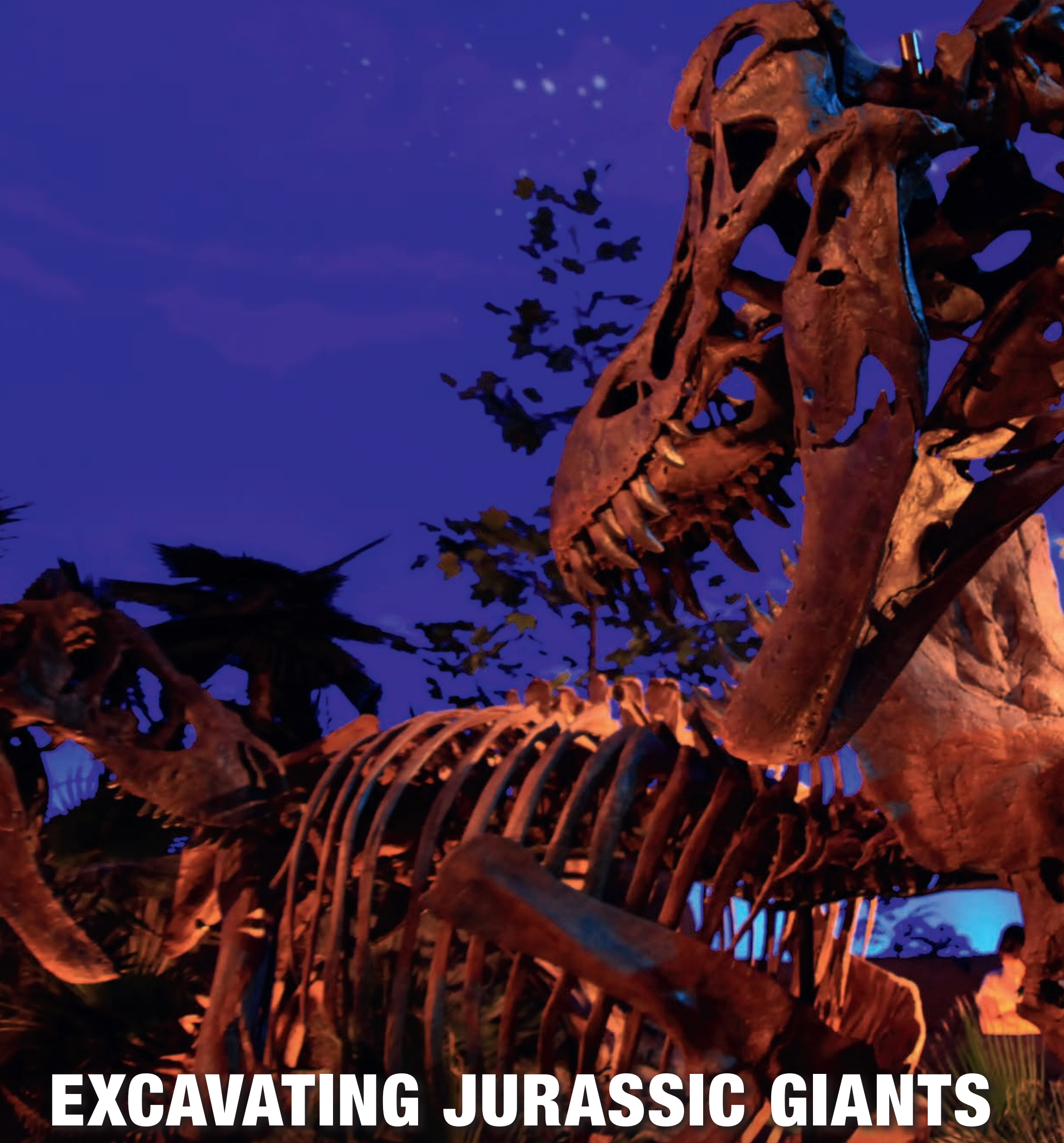

Phil Manning on an international palaeontological project to reconstruct a lost world 


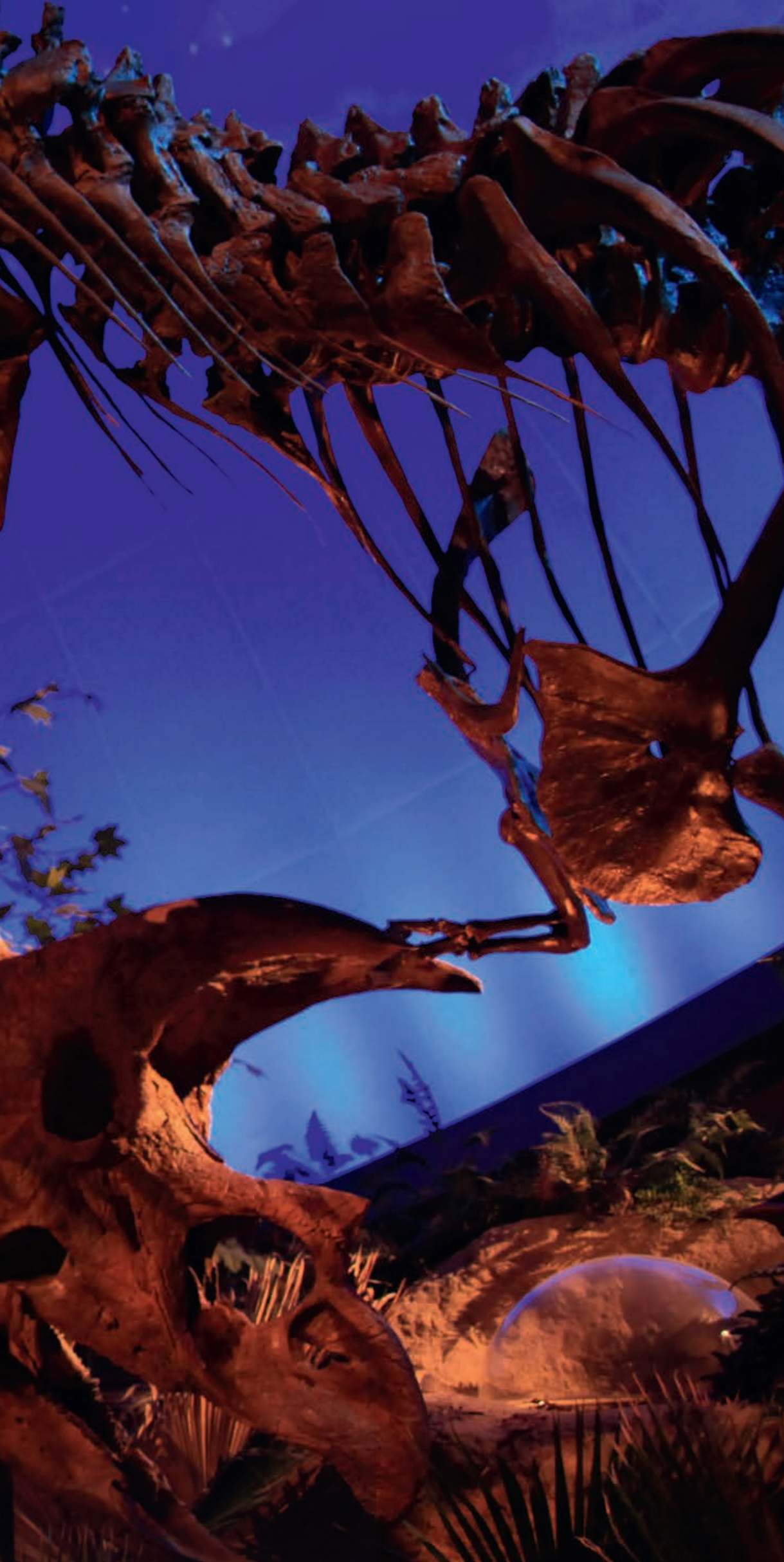

Fig 1: Dinosphere at The Children's Musuem of Indianapolis he field of palaeontology has rapidly expanded in the past few years through the application of new technology and techniques, but its roots are still firmly anchored in the Earth's past. The hindsight that the fossil record provides can help us better understand today's biosphere - it's always worth remembering that the ebb and flow of life has always been steered by the processes governing our dynamic Earth. Fossils can provide powerful insight to the past, but also to the very systems that impact our present and future planet.

The exploration and excavation of fossils still provides the critical fuel that keeps the fires of this subject burning. As each field season approaches, the palaeontological 'itchy feet' twitch. Collecting your first fossil of the season is a warm and familiar feeling that spreads through the body... but hopefully not a function of heat stroke.

\section{The Jurassic Mile}

Approximately five years ago, the University of Manchester (UoM) Interdisciplinary Centre for Ancient Life (ICAL) was approached by a team of scientists from The Children's Museum of Indianapolis (TCMI), to work on an exciting new discovery - a dinosaurbearing site in the Morrison Formation of Wyoming (USA).

The fossil remains of Cretaceous dinosaurs already populate TCMI's Dinosphere exhibit and have captivated more than 15 million visitors over the last ten years, inspiring a new generation of explorers and scientists. The new site offered the opportunity to excavate and study an area rich in fossil remains that can then be translated into a new TCMI 'Jurassic' exhibition gallery in the coming years.

Soon nicknamed 'The Jurassic Mile' by TCMI President Dr. Jeffrey Patchen, the site comprises a square mile (640 acres) of prime Wyoming Jurassic in the Bighorn Basin, close to the border with Montana (Fig 8.). Whilst vast, it offers a rare opportunity to plan and execute an excavation, and is now on a 20 year 
lease with TCM. The scale of the project has brought together scientists from across the globe, and involved collaboration with the Naturalis Biodiversity Center (NBC) in the Netherlands, London's Natural History Museum (NHM) and the Stanford Synchrotron Radiation Lightsource.

The Jurassic Project is already utilising cutting-edge science, from synchrotronbased imaging of fossils to using highperformance computers at the UoM to help resurrect the locomotor ability of Jurassic dinosaurs through stress-constrained multi-body dynamics. The project has become a productive partnership between museums and universities that has added momentum to the process of unearthing lost worlds and forgotten lives.

\section{Bone Wars}

Dinosaurs have been excavated from the Morrison Formation for over 100 years; this slice of geological time has long been associated with remains of some of the largest vertebrates to have walked the Earth. The infamous 'Bone Wars' between Yale University's Othniel Marsh and the Philadelphia Academy of Natural Science's

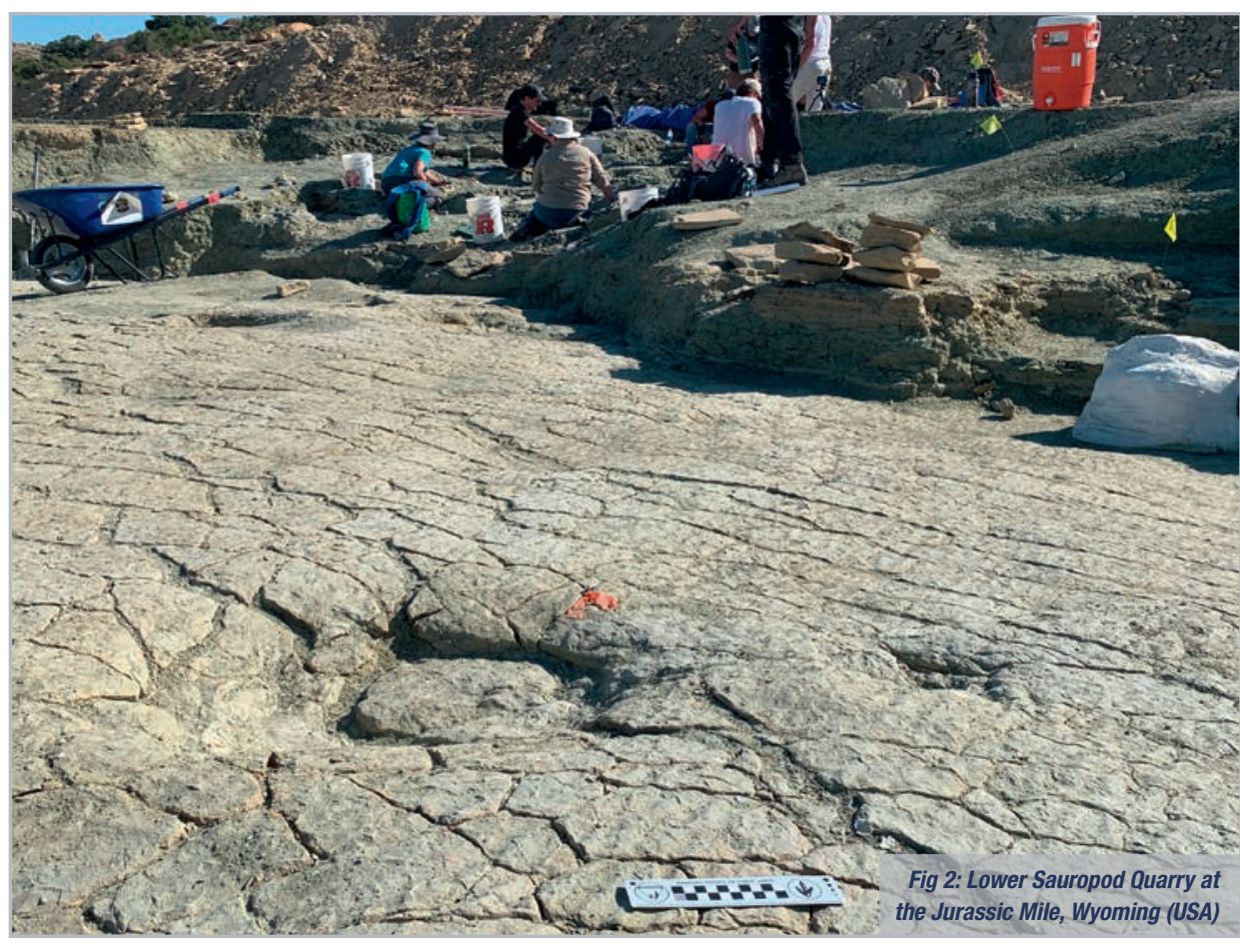

Edward Drinker Cope helped to drive the field forward at a remarkable pace- sadly, a precursor to similar pointless feuds that continue in this and many other fields of science.

The fossiliferous sediments of Como Bluff, near Medicine Bow, Wyoming, is where many of Marsh and Cope's Bone Wars took place. The large anticline ridge contains three fossil-rich Late Jurassic Formations (including the Morrison) that continue to offer new species to palaeontology. It is a historical quirk that as the Battle of Little Bighorn was playing out, a dinosaurian drama was cooccurring between the Yale and Philadelphia palaeontologists, a mere stone's throw away.

Over the past decade the Jurassic Mile had been lightly 'picked-over' by a handful of commercial collectors, but they have thankfully not made much of a dent on the locality. As stories of fossil bones from the area filtered between ranchers, collectors, and eventually museum bone-hunters in Indianapolis, the project slowly evolved. Once the site had been assessed by the TCMI and UoM team, it was clear that a 20-year lease on the square mile would yield many Jurassic fossils for the proposed expansion of TCMI's already successful Dinosphere exhibit. The lease was negotiated by TCMI and the hard work of what we now know as "Mission Jurassic" began in December 2016

I recall this timing well; our team had to fly to Wyoming to review the site and

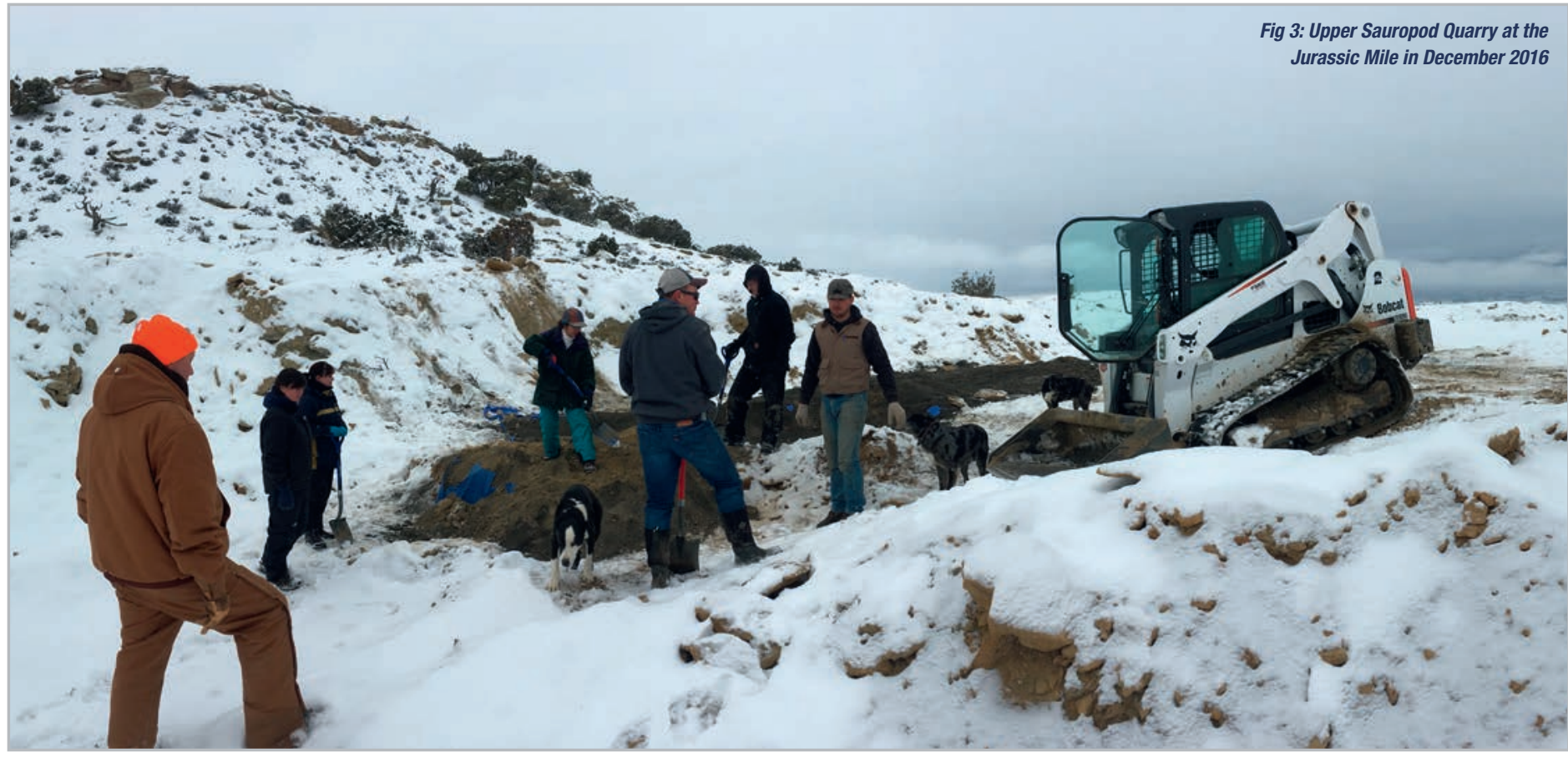


make sure that any exposed bones were suitably covered up for the Wyoming winter. Unfortunately for us, the winter arrived early and temperatures of $-30^{\circ} \mathrm{C}$ and heavy snow hampered our 'winterfying' of the site. This was without any doubt some of the coldest fieldwork our team has ever undertaken.

\section{The Morrison Formation}

The sedimentary rocks of the Jurassic Mile represent several millions of years in the geological history of Wyoming. The oldest rocks exposed that underpin the site were laid down in the Sundance Sea, a body of water that slowly retreated northwest at the end of the Jurassic in North America, now represented by the rocks of the $\sim 160$ million-year-old Sundance Formation.

These marine sediments contain a diverse fauna of invertebrate and vertebrate fossils that typify the Late Jurassic.

The TCM and UoM team have already discovered many fossils within the marine succession here, including partial skeletons of the marine reptile Baptanodon (an ophthalmosaurid ichthyosaur).

However, it was not the Jurassic marine reptiles that initially drew the team to the site, but the abundance of dinosaur bones that were in the overlying geologically

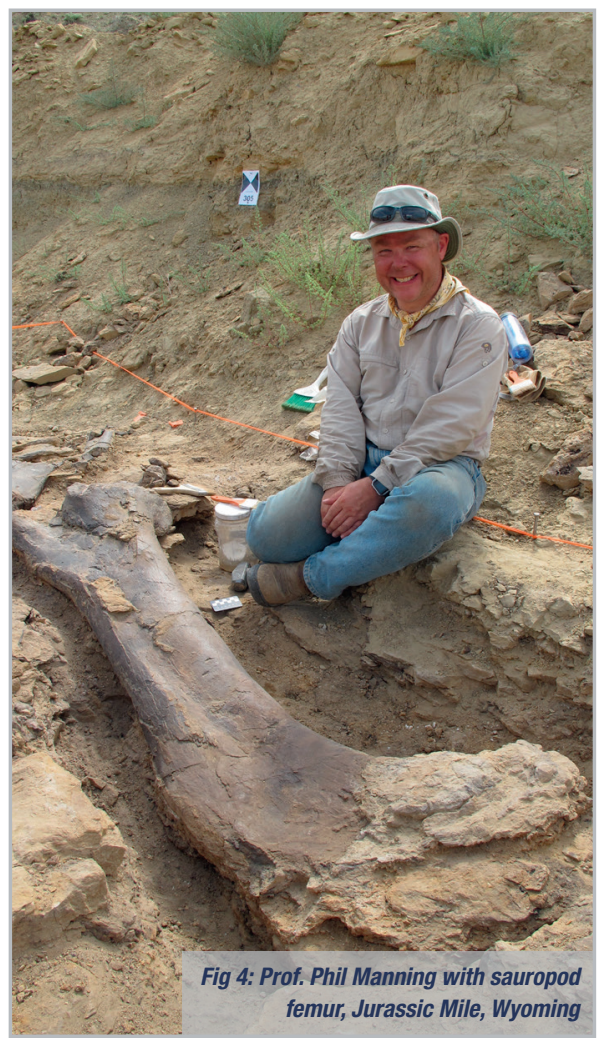

younger (approximately 150 million years old) rocks of the Morrison Formation, made so famous by Marsh and Cope.

The overlying sediments making up this terrestrial succession were laid down on a vast coastal floodplain that initially edged onto the retreating Sundance seaway, but eventually was infilled by the sediments of large meandering river systems. The sedimentary forms replay the depositional environments from the evidence preserved in their structure, composition and appearance. Over-bank muds, channelsands, sandbars and finely bedded pond/ lake deposits make up this exposure of the Morrison Formation, dominated by a repeated succession of sandstones and mudstones so typical of this Formation.

As with many such depositional systems, they were occasionally subject to environmental perturbations; sometimes slow (drought), but other times more sudden (flood). These events left their sedimentological signature written in stone, sometimes with the additional ingredient of life that had once flourished upon, alongside and/or within the said sediments. The frustration with terrestrial organisms is that they are rarely found in the precise environment in which they were adapted to live. Life has the habit of being thrown together as a phylogenetic fossil soup that can be hard to disentangle and decipher.

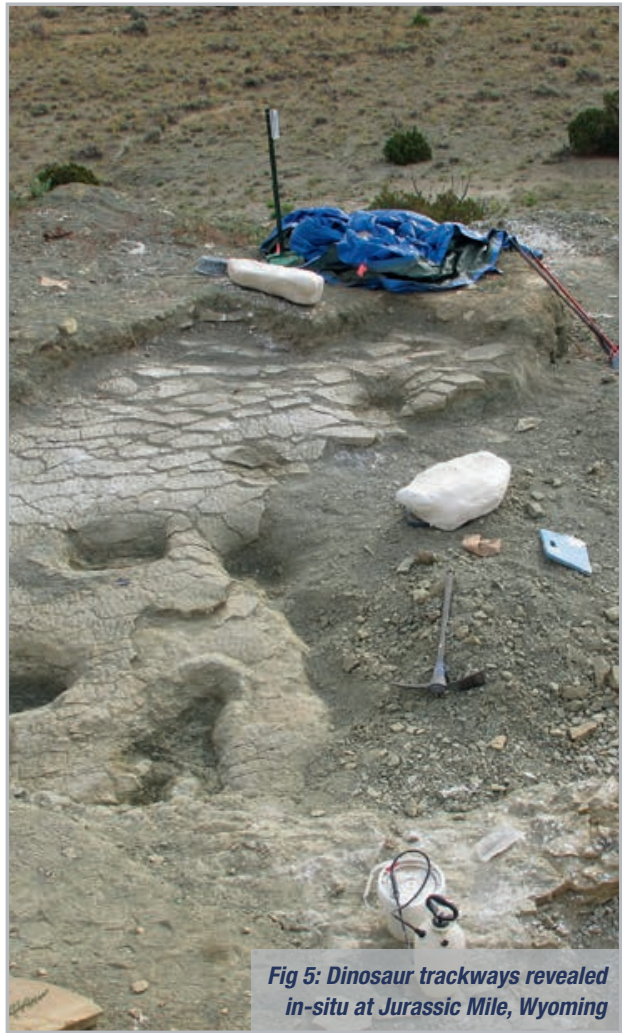

\section{A complex ecosystem}

Work at the Jurassic Mile has exposed an extraordinary number of dinosaur remains (as my post-fieldwork aches and pains attest), but unusually the site also preserves stunning dinosaur trackways and a diverse array of fossil plants that will help build a more complete picture of the ecosystem —or as complete as is possible for palaeontologists. An oft repeated 'general rule' tells us that it's rare to find a cooccurrence of associated bones, plants and trackways at the same location. One thing I have learnt in 40 years collecting fossils: if there is a 'general rule' on what 'should' be preserved, you should simply look a little harder.

The first evidence we found of tracks on the Jurassic Mile were from the spoil heaps dug by the prior 'visitors' to the site who had been working in what is now our lower Morrison Formation quarry. The huge (up to 1 metre in length) foot casts of sauropod dinosaurs had been totally overlooked, possibly due to their sheer size. A few tell-tale deformation features, not even complete tracks, were enough to alert us to their presence, albeit not in-situ. It was not long before we identified multiple track-bearing horizons throughout the succession.

It was good to discover something that had been hiding in plain sight; something

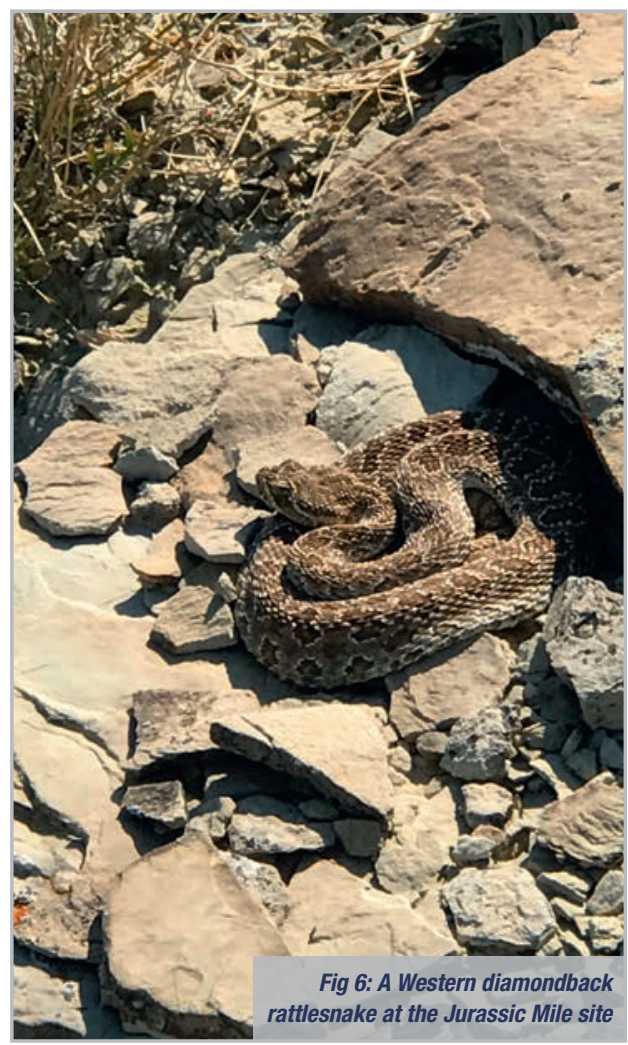


so obvious that had been overlooked for so long. The track horizons were also visible in pond/lake deposits and are often intimately associated with bone-rich layers. The dinosaur trackways were associated with the bones of sauropods (such as the famous diplodocid and macronarian sauropods) and theropod (predators such as Allosaurus) dinosaurs, which the track morphologies also reflect. These traces of movement provide powerful evidence from which the team can better understand the locomotion and ecology of these long extinct animals.

\section{'If you don’t like the weather, just wait five minutes"}

The 2019 excavation turned out to be one of the longest field seasons in my whole career. We got to site in late May, while snow was still on the ground, and were in the field until August 31st. The Jurassic Mile dig was again led by the TCMI and UoM field crews, but in 2019 we were also lucky to host teams from the NBC and London's NHM, whose staff and equipment joined the dig to explore the Jurassic Mile, contributing valuable time and equipment.

We experienced almost every type of weather you could imagine for this remote part of northern Wyoming, from snow and freezing conditions to soaring temperatures in the low $40^{\circ} \mathrm{s} \mathrm{C}$ and some of the most memorable thunderstorms I have ever suffered in the field. Some of the team had not experienced the extreme weather that Wyoming has to offer before; they soon learnt that 'bad weather' in this state was something to be respectful of. While Montana is 'Big Sky' country, I would argue Wyoming wins the 'Big Weather' award - as the rancher from whom the land is leased commented, "If you don't like the weather, just wait five minutes".

Working in the field with such changeable conditions brings its own unique set of challenges. Not least of these is figuring out an exit strategy, should a sudden storm wash out the only road from the site. Thankfully, years of forecasting the impact of weather fronts in the field combined with a careful watch of local weather patterns had our team in danger of being stuck only once...very nearly!

Getting used to the local wildlife is also a challenge - last time I looked, bears, black widow spiders, rattle snakes and scorpions weren't thick on the ground in Manchester. Many members of the team had to recalibrate their hazard awareness to account for the exotic and potentially dangerous wildlife all around us. I have never been a great fan of venomous snakes, and the venomous arthropod community was also well-represented. A big surprise to our team, especially when it was snowing, was the number of scorpions we came across as we opened up the Jurassic Mile quarries. If you believe the guide books, these beasties are rare - they are not, and should be treated with respect. Listening to advice on the presence or absence of any animals on a site, from extinct to extant, should be done with some caution.

\section{Depositional environments}

The diversity and abundance of the extinct life found at the Jurassic Mile might well stem from the multitude of depositional environments. The taphonomic 'mill' that regularly alters the fossil record has been kind to creatures discovered at the Wyoming site. Taphonomy (taphos 'burial' nomos 'laws') is the study of the processes that impact how life enters the fossil record through death, burial and fossilization. Most palaeontological studies, particularly anatomical and palaeoecological ones, depend on an ability to strip away the taphonomic overprint. This brings us to another key facet of the dinosaur bones at the Jurassic Mile - many of them are uncrushed and preserved in glorious 3D.

The burial of bones can be cruel to the survival of fine skeletal structures; often
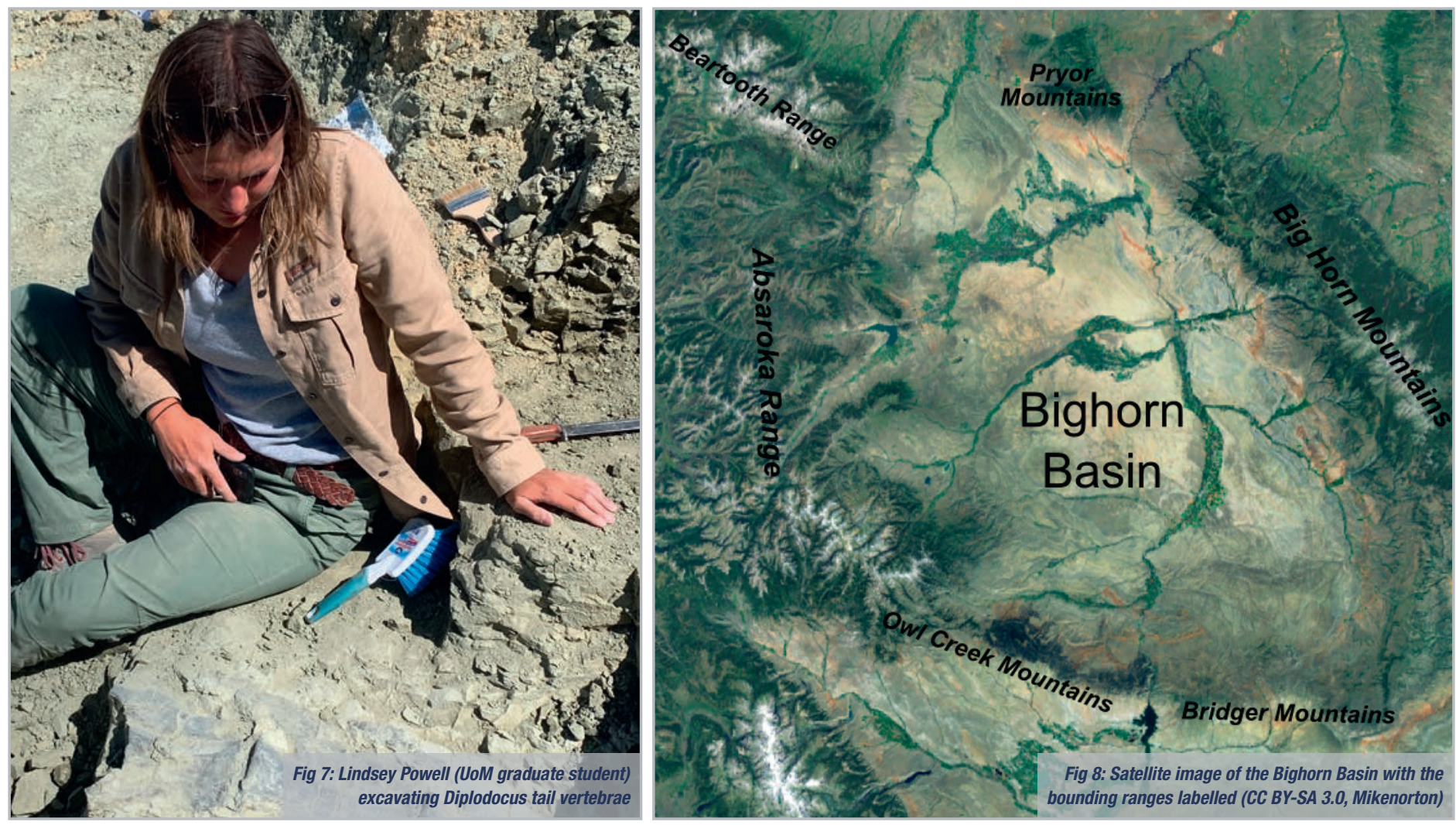
key anatomical information is lost over geological time. The bones at the new site are preserved extraordinarily well, exhibiting little to no crushing with very delicate (sub-millimetre) bone laminae surviving in-situ - in some cases for the first time in known species. The exceptionally preserved fossil plants are possibly the icing on the geological cake, offering a hitherto unseen association of plants with animals in quite specific environments (lake, overbank, pond and channel systems). The combination of all these factors makes the Jurassic Mile a perfect place to be studying this point in geological time. If you wanted to freezeframe a moment in the Jurassic to record life and the environments in which it thrived, it would be here.

While the southern Morrison sites of Arizona, New Mexico, Utah, Colorado and southern Wyoming are of both historical and scientific importance, their relationship with the Bighorn Basin sites of northern Wyoming, including our own, is not clear. The few studies that have taken place have yielded dinosaurs that do not seem to match the shape, form, and distribution seen in the Southern Morrison with what we've found in the North. Many scientists now suggest that they are not just separated in space (spatially), but also in time (temporally). The gap might only be a few millions of years, but some suggest that the northern fauna might be separated by as much as 10 million years from the southern populations.

If this separation is as long as some suspect, it is likely that many of the dinosaurs being discovered in the Bighorn Basin could represent new species. Some have gone so far as to suggest that the northern population might have been isolated from other geographic areas, which also caused distinct adaptations specific to this palaeogeographic area-this leading to speciation different from elsewhere in the Morrison Formation. One of the Mission Jurassic goals is to resolve the timing of the deposition of this location/ package of time and describe the species found within this extraordinary site.

\section{The future}

We started with a 20-year lease and now have 16 years remaining to explore, excavate and undertake the science that will hopefully help tell a fuller story of the Jurassic. The team have already invested four years exploring, mapping, and excavating the site. The next two to three will focus on placing two vast sauropod dinosaurs on display at TCMI; our current primary focus and mission. However, working with the project leads at TCMI and partners at the NBC, we hope to help further develop the Jurassic Mile's research potential in the coming years. This will no doubt involve the excavation of additional dinosaurs and hopefully the discovery of much that is new to science.

Mission Jurassic is a splendid example of international collaboration that will help to explore and hopefully resolve some of the mysteries that still exist in the Jurassic. This is also a great example of how a world-class museum (TCMI is the largest children's museum in the world!) can work with European research partners to deliver a multi-million-dollar project that benefits countless communities, both public and scientific.

Sixteen years from now, we will know so much more about a point in Earth's history when there were no polar ice caps, oxygen levels were higher, life was thriving (and very big!), and the world was rapidly changing. We live in such a changing world today and it is through studying these lost worlds and forgotten lives that we might begin to build a sustainable bridge to our own future on this fragile Earth.

by Professor Phillip L. Manning

- Chair of Natural History, Interdisciplinary Centre for Ancient Life, Department of Earth and Environmental Sciences, University of Manchester, Manchester UK.

- Scientist in Residence, The Children's Museum of Indianapolis, Indianapolis, Indiana, USA

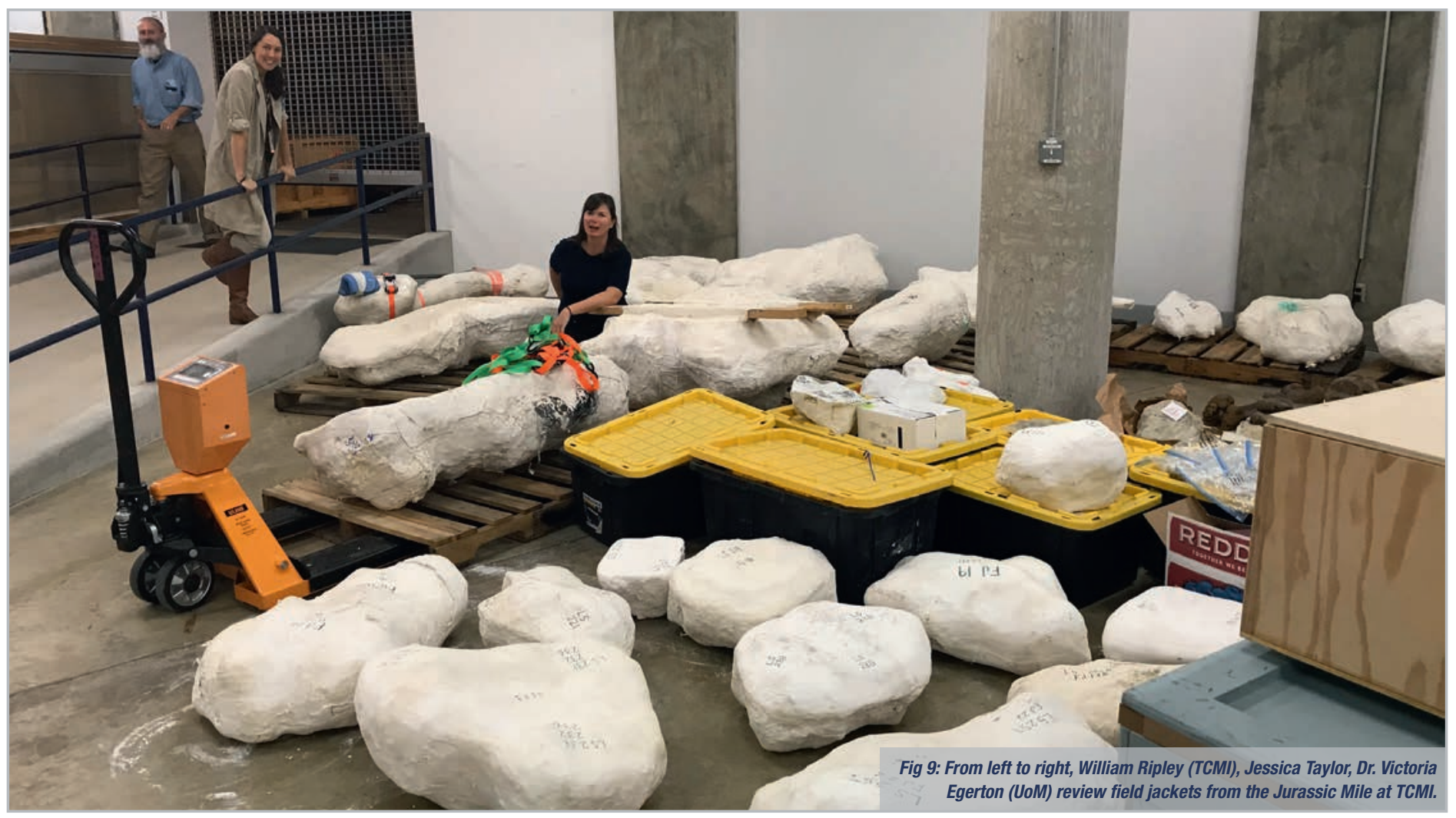

